\title{
LA FORMACIÓN HUMANÍSTICA Y EL ROL DE LOS ESTUDIOS GENERALES: Una reflexión sobre sociedad y naturaleza. Reflexiones in memorian a Jaime Bustamente
}

\author{
Msc. María Eugenia Rojas Rodríguez \\ Escuela de Estudios Generales \\ Universidad de Costa Rica.
Según su ánimo Obediente
Al dictado de los astros. Incesante y mágico
ciñendo vidas y muerte,
Murmurando incesante
Sus fugaces sílabas de sal. Y su nombre
vuela de nuestros labios
como una gaviota más. \\ ENTRE EL SUEÑO Y ELMAR \\ Jaime Bustamante Montaño \\ AHÍ ESTA, POR PRIMERA VEZ SIEMPRE \\ Todo entusiasmo o pura serenidad
}

\section{ESBELTA LIGERAMENTE INCLINADA}

Como un silencio que clarea Sobre el bullicio de la plaza

Y el rumor de la marea. Plantada

Más que en la arena

En la tenue frontera

Entre el sueño y el mar

( no sabe el aire

-menos aún el poema-

si a punto de dormirse despertar ).

\section{El viento}

La palmea. Se despereza :

Sin dar un paso

Sale con él a bailar.

Mas apenas se aleja

Vuelve a ensimismarse

En su perpetua pubertad.

Cae la noche :sueña

Con astros o peces.

Desde lo alto

Restos flotantes de una estrella

Ahogada en la tierra

A las estrellas parece.

Pero a estas alturas

ni las aves ven.

Descienden imágenes.

Mejor callar y mirarla

Donde realmente está :

Frente al mar

En la luz

cimbreante

Como una palabra

Acabada de pronunciar.

Fuente : Maradiaga, David. Dejen al Sol brillar. 


\section{INTRODUCCIÓN}

El interés de la autora de este estudio es publicar el artículo de Jaime Bustamante, y presentar al lector y en especial a los estudiosos del Humanismo la trayectoria de Jaime, así como el rol de los Estudios Generales en la formación humanística de los jóvenes que ingresan a la Universidad de Costa Rica.

Este trabajo se estructura de la siguiente manera: una primera parte introduce la vida y obra de Jaime Bustamante, en la segunda parte reproduce el escrito original de Jaime Bustamente, y una tercera, que se dedica a comentar y reflexionar el texto de Bustamante

La Educación Universitaria desempeña un rol activo reconociendo la necesidad de desarrollar una perspectiva más amplia del ámbito y de los objetivos que lleven a promover la búsqueda de un enfoque dinámico que pretende integrar al individuo a la sociedad que pertenece, llevándolo a conocer sus capacidades, potencialidades, intereses y necesidades, para transmitir el patrimonio funcional de la cultura.

La Universidad de Costa Rica en su Estatuto Orgánico establece en su título I, la misión de la universidad hacia la sociedad, veamos cuales son los principios que guían el quehacer de todos los universitarios:

\section{TÍTULO I \\ DECLARACIÓN DE PRINCIPIOS, PROPÓSITOS Y FUNCIONES}

" ARTícULO I. - La Universidad de Costa Rica es una institución autónoma de cultura superior, constituida por una comunidad de profesores, estudiantes y funcionarios administrativos, dedicada a la enseñanza, la investigación, la acción social, el estudio, la meditación, la creación artística y la difusión del conocimiento.

" ARTícULO 2. - La Universidad de Costa Rica goza de independencia para el desempeño de sus funciones y de plena capacidad jurídica para adquirir derechos y contraer

obligaciones, así como para darse su organización y gobierno propios. Su régimen decisorio es democrático y por consiguiente en ella las decisiones personales y colectivas se realizan con absoluta libertad.

" ARTíCULO 3. - El propósito de la Universidad de Costa Rica es obtener las transformaciones que la sociedad necesita para el logro del bien común, mediante una política dirigida a la $\mathrm{h}$ consecución de una verdadera justicia social, del desarrollo integral, de la libertad plena y de la total independencia del pueblo. "

La Universidad, a partir de la década del cuarenta, tiene un papel sustancial como formadora de cuadros técnicos, científicos, intelectuales y burocráticos 
para contribuir a este nuevo modelo de desarrollo nacional, que dichos sectores pueden acceder al empleo y a una mayor participación en la vida política cultural. . . De allí que las relaciones dinámicas entre la Universidad, el Estado y la sociedad, en ésta época, nos permiten comprender la problemática universitaria. (Herrera; 1994: 23).

Se pretende a partir de su fundación darle una organización unificada y estructurada en una facultad de Humanidades.

Estudios Generales se consolidó como una unidad canalizadora de las ideas humanísticas y como vertiente renovadora del quehacer universitario. Su pensamiento se centra en la formación de un ciudadano con objetivos claros, consciente de su realidad, con una formación sólida, tanto en el plano humanístico como profesional y capaz de aportar su formación al desarrollo del país.

La creación de la educación superior con características democráticas, abierta y como agente de cambio permite insertar a nuestro país en una tarea sustantiva y dinámica, que pretende la formación de profesionales con metas claras, críticos de su realidad y capaces de aportar su formación a la estructura productiva del país. Cumpliéndose de esta manera el objetivo fundamental de la Universidad pública y democrática, que promueva la transformación de acuerdo a las necesidades y circunstancias de la sociedad.

\section{HAZAR Y NECESIDAD: COMO LLEGÓ A MÍ EL DOCUMENTO DE JAIME BUSTAMENTE}

Los profesores universitarios y muy particularmente los de la Escuela de Estudios Generales revisamos una infinidad de trabajos y los reglamentos nos obligan a devolverlos al estudiante. Por una casualidad de la vida este trabajo del joven estudiante Jaime Bustamente Montaño, ( Director del

Programa Educación Ambiental, de la Asociación Ecologista

Costarricense. Trabajo cinco años en el equipo de la Comisión la

Defensa de los Derechos Humanos en Centroamérica. CODEHUCA. Formó parte de la preconferencia de Derechos Humanos en Costa Rica en Enero de 1993. Participó en la conferencia mundial de Derechos Humanos en Viena, Austria en junio de 1993 ), quedó entre los papeles viejos que a final de año todos hacemos desaparecer. azar o necesidad? Cuando hace como 4 años debí de haberme desecho de este trabajo, al revisarlo encontré una atracción en el texto que me hizo guardarlo.

Pude haberlo guardado sólo como un recuerdo personal, pero me he decidido a compartirlo con ustedes porque hay razones de peso. Mi experiencia de profesora de la cátedra de Historia de la Cultura y el encontrarse un estudiante maduro que ya hoy no esta entre nosotros, pero que el curso lo llevo

a realizar una reflexión universal en sus contenidos.

El artículo de Jaime me hizo pensar en el rol de profesora de Estudios Generales y en esa oportunidad que enfrentamos a diario en las aulas de poder intercambiar con jóvenes que seguirán diferentes caminos 
profesionales pero que los Estudios Generales los llevan a plantearse asuntos que trascienden la vida provinciana de los problemas nacionales.

En esta riqueza de educar para la libertad, de educar para la universalidad es que el trabajo de Jaime viene a reforzar en todos los que enseñamos desde una cátedra ese hálito de vida, esa retroalimentación que hace de la educación un poco algo de aventura, ya que no conocemos el camino final de nuestras enseñanzas.

Pero saber que se sirve de cimiente para que las nuevas generaciones que año a año desfilan por aquel edificio se impregnen de un cuerpo de conocimiento que los lleve a ampliar las fronteras de lo que hasta ese entonces pueden conocer es en ese momento preciso que la universidad alcanza su cometido de universalidad y es cuando la educación deja de ser un trabajo para convertirse en una vocación.

Cuando sucedió el fatal desenlace que cegó la vida de aquellos tres jóvenes estudiantes me dolió profundamente por los tres y en particular por Jaime, por la experiencia de haberlo tenido como estudiante. Pero en ese momento no volví a recordar el documento que había guardado en mi biblioteca.

Hace como un año acomodando mis libros me volví a encontrar con el trabajo de Jaime y me sumí de nuevo en el texto y en los recuerdos de aquel grupo de estudiantes y del desenlace tan trágico que tuvo la vida de Jaime, al leer el texto me encontré no ya con el texto de Jaime sino con mi labor profesional, con mi labor como profesora de una Escuela tan importante del en el quehacer intelectual de los estudiante Universitarios.

El haber guardado estas notas me llevaron a pensar en sistematizar un texto que sirviendo de homenaje póstumo a mi alumno, me planteará también el rol de los Estudios Generales y de la Cátedra de Historia de la Cultura. De manera que este ensayo reúne dos elementos el trabajo de Jaime, quizás el único testimonio escrito de un gran valor intelectual acaecido trágicamente y el itinerario de un profesor que tiene que enseñar unos contenidos con sus estudiantes.

Jaime me facilitó la tarea de resumir el contenido de un curso, pero me enseñó a que los contenidos los estudiantes los sistematizan de diferente manera y que muchas veces no responden al ideario del que los enseñó. Y ese es un valor fundamental de los Estudios Generales la Libertad como guía del aprendizaje.

Jaime tenía una predisposición para absorber las ideas y ubicarlas dentro del paradigma en el que él se estaba forjando. Su lucha por la naturaleza y la protección ambiental ya estaban presentes al momento de llegar al la escuela de Estudios Generales, nuestro objetivo era enriquecer y llevar a confrontar sus ideas con otros paradigmas, para que se diera un verdadero crecimiento intelectual. 
Como lo escribe su amigo Alejandro:

"Bueno, retomando lo de Jaime y la naturaleza, nunca nos fuimos a vivir a la montaña según lo planeado en aquel primer encuentro, pero sí hicimos algunas comuniones con ella. Soy testigo, repito, del placer que siempre él encontró en el verde, la brisa, un arroyo de la montaña, la fascinación del mar. Pero no sólo por eso digo que sí era un ecologista de corazón. Lo afirmo además porque, insisto, su vocación era creer en el futuro, tener fe, tener esperanza; es más, el hilo conductor de su vida fue ese aferrarse al futuro idealizado; gustaba de la palabra utopía y la utilizaba mucho. . . . Su interés más que demostrado en conservar las riquezas naturales del Golfo Dulce, o del hermoso bosque que él "descubrió" en un confín de la zona de San Ignacio de Acosta llamado El Cornelio, o de ese último refugio que le quedó en el Valle Central al Hauya lucida, endémico de la meseta: Las Lomas del Salitral, tan queridas a Jaime " (10 de enero de 1995, en casa de Jaime ). Alejandro Román,

Sí como profesor se logra este cometido estamos cumpliendo con la misión de la universidad. Estoy segura que Jaime encontró en la Universidad y en los Estudios Generales, interlocutores y muchos compañeros con quien confrontar las ideas que el tanto defendió. Ya fuera de las aulas universitarias perseveró y se forjó como un luchador por la naturaleza, por la preservación del planeta.

Mi tarea como docente era que esas ideas emergieran con la mayor libertad y naturalidad en un estudiante que viniendo de Bolivia tenía un conocimiento empírico muy rico y que había que fortalecer con una dosis de metodología y de pedagogía.

Para la concepción interpretativa, investigar es comprender la conducta humana Desde los significados e intenciones de los sujetos que intervienen en el escenario educativo. Desde esta perspectiva el propósito es interpretar y comprender los fenómenos educativos a través de una concepción democrática del conocimiento y de los procesos que lo generan mediante la participación de las personas implicadas.

Por los cual Arnal, explica que " La perspectiva interpretativa penetra En el mundo personal de los sujetos ( como interpretan las situaciones, que significan para ellos,que intenciones tienen ). Busca la objetividad en el ámbito de los significados utilizando como criterio de evidencia el acuerdo intersubjetivo en el contexto educativo. ( Arnal,1994,41).

Jaime Bustamante, representó a la persona libre en una sociedad libre, desarrolló las facultades de expresión, reflexión y deliberación, donde la convivencia le permitió innumerables relaciones con la libertad de la persona. Y la libertad social, actitudes y motivaciones estrechamente ligadas al concepto de libertad humana y de compromiso social que lo llevo a concebir,sin ningún temor en su discurso, a un ideal de persona y sociedad. 
La preocupación fundamental de Jaime, fue no solo enfrentar los problemas que agobian al hombre (especialmente la depredación del medio ambiente) sino, también, orientar acerca de las posibles maneras de enfocarlos hacia sus posibles soluciones, o al menos a sus planteamientos correctos.

Así lo manifiesta el siguiente texto, facilitado por el señor Alvaro León Chavez

\section{" PARA QUE EL FUTURO NO SEA SOLO UNA ESPERANZA}

El 7 de diciembre de 1994 se despidió de nosotros el compañero Jaime Bustamante, miembro protagónico en la construcción del movimiento popular y ambiental. Junto con Oscar Fallas y María del Mar Cordero fallecieron en un trágico incendio. Los tres fueron pilares fundamentales de la Asociación Ecologista Costarricense (AECO), desde donde aportaron sus mejores ideas y esfuerzos para construir una nueva realidad socialmente justa y ambientalmente sana. Oscar desde su puesto como Presidente y Director Ejecutivo, María como Directora de Campañas y Jaime como Coordinador de Educación Ambiental. Cada uno con sus características y talentos individuales entregaron toda su energía a las comunidades del norte, el centro y el sur de Costa Rica.

Jaime, de treinta y seis años se desarrolló un trabajo de organización y concertación en el Cantón de Desamparados, donde colaboró con el Proyecto Hábitat Alternativo en Los Guidos, con la Comisión Ambiental Desamparadeña que luego se transformó en el Movimiento Ambiental Desamparadeño (MAD) y, fundamentalmente, en la Campaña para la declaración de protección del área conocida como las Lomas de Salitral, proyecto por el que han luchado desde hace mucho tiempo personas e instituciones del cantón. Con gran cariño, el Flaco como todos le decíamos, se hizo eco del deseo de los vecinos por constituir las lomas en un área de Protección Ambiental Urbana, la primera en su tipo en el país. Organizó con las comunidades giras científicas y recreativas, escribió proyectos e inventarios de la riqueza natural, llevó a cabo el Festival Ecologista por las Lomas y divulgó por la prensa escrita y la televisión la importancia de este pulmón verde del cantón desamparadeño.

Asímismo, Jaime también fue el coordinador de los Seminarios de Hábitat y Ambiente en Desamparados que trataron temas como Desechos, Conservación y Planificación Urbanística, con el objetivo de dar una mejor calidad de vida a todos los habitantes. En estos foros logró congregar las voluntades de las organizaciones comunales, de los funcionarios públicos y de la comunidad científica y universitaria, orientando sus esfuerzos a proyectos concretos que promovió y defendió en diferentes instancias nacionales.

Apasionado por el conocimiento Jaime se dedicó a la investigación y la educación popular. El mismo niño silencioso que devoraba los libros mientras se nutría de las enseñanzas del abuelo materno en su Bolivia natal, el mismo adolescente inquieto que dejó la calidez y comodidad del hogar de sus padres, para comprender brazo a brazo con los campesinos el valor del trabajo y de la 
agradecida fertilidad de una tierra cada vez más degradada. Hace catorce años llegó a Costa Rica y desde entonces estuvo vinculado a los movimientos artísticos-literarios de nuestro país. En 1992 publicó parte de sus poemas en la antología "Dejen al sol brillar". Participó en gran cantidad de recitales y encuentros donde dejó una notable impresión por su sensibilidad e inteligencia.

Joven siempre, organizó también muchas actividades para este sector, entre ellas el Encuentro Juventud y Ambiente Urbano, en 1991, la Consulta Nacional de la Juventud, la Consulta Latinoamericana y el Foro Mundial de la Juventud sobre Ambiente y Desarrollo. Para estas actividades escribió un documento sobre los temas de la Cumbre de Río de Janeiro que fue publicado en el libro El continente que queremos, en 1992.

Uno de sus principales aportes a la AECO fue la redacción del PDI (Proyecto de Desarrollo Institucional), documento de gran trascendencia en el quehacer actual de la Asociación.

Alegre, entusiasta, su recuerdo quedará grabado para siempre en todos los que tuvimos el honor de conocerlo y compartir sus sueños, como un aliento permanente: "para que el futuro no sea sólo una esperanza".

Artículo elaborado por:

Movimiento Ambiental Desamparadeño (MAD) ".

Cuando Jaime llegó ( después de casi una década de haber interrumpido sus estudios ), a la Escuela de Estudios Generales de la Universidad de Costa Rica, manifestó, que este centro de estudio representaba para él todo un reto pero que estaba seguro que su formación personal, cultural social y ciudadana se reafirmaría con esmero y energía.

Efectivamente, más tarde,mi joven estudiante demostró sus calidades humanas, culturales y sociales, integrando sus conocimientos,con la formación humanística recibida en la Escuela de Estudios Generales lo que le ayudó asumir una posición crítica y beligerante como profesional, pero sobre todo como ser humano.

A través de sus trabajos, Jaime dejó en claro su convicción de que los pensamientos se deben poner en práctica, él pertenecía a una generación, con una gran responsabilidad de sus congéneres futuros, Por ello la tarea ineludible es que el ser humano entienda : que vivir es tratar con el mundo, y ocuparse de él, faena un tanto difícil, pero la sociedad debe buscar la fórmula precisa, en donde la unificación del saber y el sentido común lleven por buen camino el destino del planeta.

Al respecto Jaime afirma " La realización de la Conferencia Mundial de los Derechos Humanos se llevará a cabo después de más de 25 años - la última se llevó a cabo en Teherán en 1968 - y encuentra al mundo en una serie de cambios trascendentales a nivel político y económico, en donde la evolución de 
la normativa internacional y la emergencia reinvindicativa de nuevos sujetos sociales que exigen la plena vigencia de los derechos humanos y el reconocimiento de otros marca su trascendencia histórica, pues foros como estos,son por decirlo

así, los ámbitos éticos que aún conserva la comunidad internacional para dirimir

pacificamente los conflictos y para construir Sociedades y Estados basados en principios inalienables compartidos " ( Carta personal de fecha1993. 1)

Se desprende de las frases anteriormente mencionadas que Jaime se aboca al análisis crítico de la problemática nacional e internacional, desde puntos de vista filosóficos y educativos tratando de que sus predicas se concreten en la realidad social para que el mecanismo ideológico dominante sea desenmascarado y de esta manera la sociedad adquiera conciencia de su problemática. Todo esto es producto intercambio entre su labor profesional y del flujo de conocimientos que actúa, dándose un reflejo de la sociedad misma lo que permite un análisis crítico, y a la vez lleva a la una acción social, orientada a la transformación de la realidad y como lo señala Jaime a continuación

\section{DOMINA Y VENCERÁS: CONSIDERACIONES SOBRE LA MILITARIZACIÓN DE LAS SOCIEDADES Y LOS ESTADOS Y SOBRE LA PAZ MUNDIAL.} Jaime Bustamante

Todos los que compartimos la responsabilidad presente y futura de evitar que la experiencia de Hiroshima, de las guerras entre naciones, de las intervenciones militares extranjeras, del armamentismo y la militarización de las sociedades y estados, se conviertan en parte consustancial de la cultura en la que nos ha tocado heredar, vivir y construir, se nos presenta como un gran reto, pensar los problemas de la seguridad, de la defensa de la vida humana y del entorno que lo hace realizable y de la convivencia nacional e internacional con otros ojos y con otra concepción a la establecida, para lograr, como generación, proponer vivir en paz y en armonía con la naturaleza.

Para tales fines se esbozan los aspectos centrales de lo que a nuestro juicio constituyen problemáticas y realidades que enmarcan las acciones que como generación debemos de realizar en este campo.

\section{SOBRE LA SEGURIDAD}

La idea de la seguridad predominante en las relaciones internacionales esta sentada sobre la base de una concepción militar: el estado-nación moderno preserva su soberanía y su sistema económico mediante una política de defensa manifiestas en sus fuerzas armadas. Así cada Estado se relaciona con los demás a partir de su poder económico y militar. Como consecuencia las relaciones internacionales se conforman de acuerdo a la tensión entre las estado más fuertes y menos fuertes. 
Desde la postguerra las relaciones basadas en el poder y la fuerza han signado nuestro mundo determinándolo. La bipolaridad Este-Oeste que desarrollo la guerra Fría posibilito el crecimiento sin precedentes de una carrera armamentista en la que la superioridad de uno debía de ser compensada con esfuerzos inusitados para construir instrumentos de destrucción y de muerte por el otro. Los recelos y la paranoia caracterizaron este periodo político en el que tanto los países del Norte como de los de Sur participaron como veremos de una manera u otra.

Este inaceptable fomento de la seguridad hizo posible la perspectiva de la aniquilación de la civilización humana. El futuro de la humanidad pasó a ser entonces un rehén para garantizar la seguridad de unos pocos estados poseedores de armas nucleares y, en especial, de las dos superpotencias.

El concepto del mantenimiento de la paz, la estabilidad y el equilibrio mundiales mediante el proceso de disuasión es tal vez la falacia colectiva más peligrosa en la actualidad. La guerra del Golfo Pérsico pudo comprobar su función. Una vez declarada unilateralmente el fin de la guerra Fría por la Unión Soviética, emergió por la fuerza de la imposición y la destrucción la misma concepción de seguridad mundial y de pax mundial, pero ahora ya no con dos superpotencias sino con el papel militar de uno y la alianza con muchos otros que comparten el interés económico de un nuevo globalismo, el nuevo orden internacional.

La bomba atómica que borró del mapa a Hiroshima tuvo una potencia de 13 kilotones, o sea el equivalente a 13. 000 toneladas de dinamita. Actualmente los arsenales de las llamadas superpotencias nucleares cuentan no con una, sino con numerosas bombas nucleares de 20 megatones o sea el equivalente de 20 millones de toneladas de dinamita

El total de ojivas existentes se calcula en 50 . 000, con una potencia explosiva bastante cercana a la de un millón de bombas como las de Hiroshima, cuyo poder destructivo implicaría unas cuatro toneladas de dinamita para cada habitante de la tierra.

Los efectos de las armas nucleares son, no solo un calor intensísimo y una irresistible onda de choque sino también precipitaciones radioactivas cuyos efectos retardados pueden prolongarse por décadas. Además de la explosión calor y las radicaciones la guerra nuclear, aun en una escala limitada produciría humo, hollín y polvo en cantidades suficientes para desatar un invierno nuclear que podría transformar a la tierra en un planeta helado y oscuro, en condiciones tales que significaría la extinción de especies en magnitudes sin precedentes.

Esta eficacia macabra en la letalidad de las armas, y las consecuencias que traerían su aplicación comienza a ser preocupación de varios estados pero sobre todo de la sociedad civil y del movimiento ecologista en el planeta. 
La idea de la seguridad comienza a ser redefinida paradójicamente pues la lluvia ácida o el efecto de invernadero no respeta fronteras. El accidente de Chernobil es un ejemplo de esta situación.

\section{SOBRE LA IMPERIOSA NECESIDAD DE DESARME}

La Declaraci6n de Nueva Dehli suscrita el 28 de enero de 1985 por los jefes de Estado de Argentina, Grecia, LA India, Suecia, Tanzania, y México. "Casi imperceptiblemente, durante los cuatro últimos decenios, cada nació y cada ser humano ha venido perdiendo la facultad de controlar, en ultima instancia, su propia vida y su propia muerte. Un reducido grupo de hombres y de máquinas en ciudades lejanas puede decidir el destino de todos nosotros. Asimismo, la Asamblea General de la ONU en la. Campaña Mundial contra el Desarme manifestó "La tarea más crítica y urgente de momento es eliminar la amenaza de una guerra nuclear. La humanidad se halla ante un dilema: debemos detener la carrera armamentista y proceder al desarme o enfrentarnos a la aniquilación".

Estas consideraciones llevaron a los presidentes Reagan y Gorvachov a iniciar conversaciones sobre la reducción de armas nucleares no convencionales pero también existieron otras que tuvieron quizás mayor peso que las valoraciones éticas y morales, que fueron las razones económicas. La industria bélica y los gastos de defensa constituyen trabajos improductivos. La guerra significa al fin de cuentas destrucción de riqueza para imponer o conservar relaciones sociales.

Los países industrializados con un reducido gasto de defensa en la postguerra como Japón, Alemania, Suiza etc, han tenido un mayor crecimiento económico que países con un gasto militar relativamente fuerte como Estados Unidos Francia, Gran Bretaña y la URSS.

La carrera armamentista llevó a la Unión Soviética a una carrera sin sentido, alcanzando como el resto de los países del complejo industrial militar una capacidad asombrosa para acabar con toda la humanidad. Desde el Punto de vista de la seguridad nacional, la carrera armamentista se volvió cada vez más absurda. Desde el punto de vista del crecimiento económico, el gigantesco gasto improductivo limitó las inversiones productivas, estancando la economía civil y la de las necesidades populares.

La ONU tiene una larga historia de resoluciones e informes especiales de su Asamblea General que vinculan el desarme con el desarrollo. En muchos de ellos se señala que una parte de los ahorros que se logren a raíz de los acuerdos del desarme se destine a la ayuda económica del Tercer Mundo.

La propuesta más reciente en este sentido la presentó el Gobierno de Francia cuyo proyecto para crear un Fondo Internacional para el Desarrollo y el desarme se trato en la Conferencia de la ONU sobre Desarme y Desarrollo, Celebrada en París en Julio y Agosto de 1986. 
Por otra parte América Latina es la unión región del mundo que ha sido declarada desnuclearizada. El Tratado de Tlatelcolco prohibe que los países de América Latina fabriquen, utilicen o adquieran armas nucleares por cualquier medio, así como recibirlas, almacenarlas, poseerlas, probarlas o desplegarlas. No obstante es poco lo que se ha avanzado en relación a armas convencionales. En la mayor parte de las discusiones se aborda sobre todo el control de los conflictos, dejando a un lado las posibilidades reales del desarme y el desarrollo de las formas como podría llevarse a cabo.

El 9 de diciembre de 197 , ' los representantes de los siete países miembros del Pacto Andino (Bolivia, Colombia, Chile, Ecuador, Perú Y Venezuela) y otros dos países miembros (Panamá y Argentina) firmaron en Lima la declaración de Ayacucho. El documento incluye el acuerdo para "promover y apoyar un orden permanente de paz y de cooperación internacional, y para crear las condiciones que permitan un control eficaz del armamento y que propongan fin a su adquisición para fines militares ofensivos, con el objetivo de destinar todos los recursos posibles, al desarrollo social y económico de los países de América Latina. ¿Por qué ha sido imposible llevar a la práctica la declaración de Ayacucho?

\section{SOBRE EL PROBLEMA DEL GASTO MILITAR COMO CARGA SOCIAL.}

El consecuente incremento de los gastos militares de las principales potencias, la intensificación de la carrera armamentista, los conflictos armados en diversas regiones del tercer mundo y la intervención de las potencias en muchos de ellos, configuran por decirlo así la cadena dependiente de los gastos militares impuestos. Los gastos militares del tercer mundo han crecido en términos reales de manera significativa desde la terminación de la segunda guerra mundial y se han mas que triplicado en los últimos 20 años. Casi el $80 \%$ de las erogaciones de defensa de 1984 correspondió a los países desarrollados. Además desde fines de la década de los sesentas los gastos militares de estos países crecen a una tasa mucho mayor que las de los del tercer mundo.

Los vínculos que existen entre la internacionalizaci6n del capital, el armamentismo y el subdesarrollo se comprueba con el peso que ha tenido los presupuestos militares en cada uno de los estados nación. Así lo militar aparece como agente del subdesarrollo, es decir, un mecanismo que sirve para extraer el excedente producido en la periferia, con el fin de apoyar la acumulación capitalista en la metrópoli.

La magnitud de las erogaciones de los países en armamento no depende solamente de las necesidades de "seguridad nacional", sino también de las previsiones de los países productores de armas, la competencia entre los proveedores y la intromisión política. La magnitud de sus erogaciones se debe principalmente a los conflictos generados o apoyados desde el exterior y que consisten sobre todo en la adquisición de armas. 
La crisis mundial ha debilitado económicamente a América Latina, junto con el resto del Tercer Mundo. Su deuda externa ha crecido, las tasas de interés se han multiplicado y el servicio de la deuda absorbe una proporción muy grande de sus ingresos por exportaciones. Ciertamente en ocasiones esta situación ha obligado a los gobiernos a restringir el gasto publico, incluyendo el militar, como parte de las medidas de austeridad impuestas en los programas de ajuste del FMI. Sin embargo los factores estructurales que genera el gasto militar entre ellos la economía armamentista internacional permanecen intactos.

\section{SOBRE LA MILITARIZACIÓN DE LA SOCIEDAD}

La militarización de la sociedad actual más que un peligro es un hecho que tiene unas dimensiones universales y unas consecuencias nefastas para la paz. Algunas características del militarismo en las sociedades que merecen estudiarse son:

- El incremento acelerado del gasto público dedicado a fines bélicos.

- El desarrollo de una ideología de la crisis cuya solución es fundamentalista, individualista y violenta.

- La población activa ocupada en actividades directamente militares.

- El desdibujamiento de las fronteras entre actividades civiles y militares, particularmente en los campos de la investigación y de la enseñanza. Frecuentemente los sujetos de tales actividades ignoran el uso, que al margen de sus deseos y convicciones, se hará del fruto de su trabajo. - La difusión de una cultura belicista hábilmente enmascarada que abarca desde los juegos infantiles hasta la fabricación de mitos populares para el consumo de masas: Rambo, etc.

- La militarización constituye un freno al desarrollo y a la democracia tanto por la desatención de las necesidades sociales como por su papel represivo garante de la injusta distribución del ingreso y de la calidad de vida al interior de los países.

Coma diría un selecto grupo de pensadores latinoamericanos la guerra es un negocio sucio que demanda chantaje, mentira, el desprecio, la arrogancia y la prevalencia de los instintos de destructividad y de muerte orientados contra el ser de los hombres en sentido genérico, y contra sus recursos de vida. Esto último es hoy mas patente y dramático debido al desarrollo de las tecnologías y procedimientos de guerra. Pero si la guerra es un negocio sucio ella no admite héroes ni grandes causa ni palabras. No existe ningún motivo legítimamente humano para admirar o disfrutar de la guerra. El que muchos sectores no reparen en la indecencia básica de una guerra de agresión, es una de las

- materializaciones criminales de una sociedad de destructividad y de muerte que hemos contribuido históricamente a conformar; sociedad agresora que

- esta en la base de nuestra sensibilidad moral y que suele tornarnos incapaces de experimentar una real solidaridad hacia otros seres humanos, y que, en especial, nos lleva a considerar a esos otros seres humanos, y en particular a los pobres y diferentes como enemigos, buscando y 
procurando para ellos, con todos nuestros medios o con nuestra indiferencia, y todo el tiempo, su destrucción y su muerte.

- Finalmente si se logran acuerdos significativos para el control de armas nucleares y convencionales, se redujeran los gastos militares del norte y se aceptara una mayor participación de los países en vías de desarrollo en las relaciones económicas internacionales, si se elimina el concepto de seguridad militar por uno más amplio que contemple una seguridad ambiental y alimentaria integrada a lo nacional, regional y global que facilite la construcción de sociedades mas justas e igualitarias y si se desecha de una vez por todas la guerra como forma de solucionar los conflictos y las diferencias, mejorarían las posibilidades de dar un tratamiento mas adecuado a los problemas globales más graves como la pobreza absoluta en el tercer mundo.

\section{UNA REFLEXIÓN FINAL SOBRE EL TEXTO DE JAIME BUSTAMENTE}

Definitivamente la educación es un instrumento de cambio que deben utilizar los educadores los intelectuales y los estudiantes para transformar la realidad social, a través de nuevos modos de acción educativa, en dónde el conocimiento permite visualizar un enfoque más amplio, revalorando preocupaciones y afanes de nuestra cultura y sociedad actual, llegando así a una mejor comprensión de lo que sucede en nuestro actual mundo histórico.

En su análisis Jaime utiliza de manera vehemente el paradigma cualitativo, con una perspectiva humanista, con énfasis en el lenguaje, en la interpretación de los hechos humanos. Su objeto de estudio es el acercamiento de la conciencia, tratando de estructurar la realidad y la comprensión de los conceptos permitiendo una mayor fluidez a la investigación social, de esta manera los fenómenos estudiados pueden llegar a ser una explicación y comprensión de la situación.

Se puede incluir en este estudios hábitos costumbres,capacidades, facultades virtudes, tendencias o como se quiera llamar a las determinaciones constituidas de comportamiento humano, esto lleva a que la investigación tenga características subjetivas al lado de ser también descriptiva e inductiva, tratando de que sus relatos sean válidos gracias al método empleado.

Al respecto resulta interesante el comentario de Dobles,cuando sintetiza las características, competencias y virtudes del método cualitativo, indicando la responsabilidad que asume el autor al utilizar esta disciplina de estudio.

" Este enfoque trata, por medio de la empatía, de comprender los motivos detrás de las reacciones humanas,y de esta manera lograr una aprehensión global de la experiencia humana Ampliando la perspectiva y tratando de comprender a los seres humanos como individuos en su totalidad y su propio contexto ". (Dobles, 1996). 
El trabajo de Jaime se destaca por la forma como enfoca la temática del Curso de Historia de la Cultura. Además de hacer un análisis de contenidos, traslapa una valoración muy significativa que lo lleva a considerar toda una reflexión en la cuál no solo es para su preparación académica, estar al día con temas en boga, sino también en las actitudes y aptitudes que asuma un profesional.

No se trata, entonces de aprender sólo, para un curso, sino que desempeña los papeles a los que se refiere su misión como ser humano, capaz, con pleno conocimiento, de defender, justificar y poner en práctica sus ideales, de analizarlas, de constituirse su propio método en función del ambiente en que se desenvuelve y de sus propias concepciones filosóficas. Su obra tiene un signo distintivo de aquel que ha sido responsable de su realización.

Jaime Bustamante trata el fenómeno del poder como un tema fundamental, se desprende de sus ideas que el egoísmo y el deseo de poder de los hombres lo lleva a la toma de decisiones atroces en el marco de todas las relaciones sociales. Ante esta coyuntura él propone la dinámica de la movilización de la participación social y la demanda de los diferentes sectores sociales, para que promuevan esa colaboración dinámica de la sociedad que gira en torno a la producción, como reproductor de la estructura de poder, de la que es parte y garante, de ahí la importancia de la dimensión hegemónica, genera formas de dominación económica y social que llevan a la dominación tanto de consenso como el aparato coercitivo,esta manipulación permite que el poder sea eficaz tanto en el uso de los recursos materiales como en los ideológicos

La lucha por el poder, explica Jaime es universal en tiempo y espacio en donde concurren y compiten los intereses particulares, reflejando la interacción de los factores que definen el poder a nivel internacional : militares, geo estratégicos, económicos. Ante este discurso mantiene, el autor una actitud contestataria y afirma que la conciencia política de los países pobres, debe ensancharse y demandar los, diferentes sectores sociales su participación en la solución de las fuertes tensiones y convulsiones a que son sometidos por la dinámica en que se desarrolla el poder a nivel mundial.

Los cambios vertiginosos que vivimos, con frecuencia van aparejadas con el desarrollo científico - tecnológico, tratan también de grandes virajes en el. Equilibrio del poder mundial, del colapso de imperios ( soviético ), del resurgimiento de nacionalismos, del desplome de ideologías políticas. Todos estos eventos plantean importantes dudas, interrogantes y oportunidades para la reflexión y la acción.

Jaime, busca una adecuada alternativa política, ideológica y educativa, que convine el crecimiento económico con justicia social y el bienestar de los ciudadanos, se requiere por lo visto, mucha flexibilidad para adaptarse a los cambios 0 , incluso para propiciarlos, y mucha entereza para poner en práctica los nuevos lineamientos para construir un futuro mejor.

\section{CONCLUSIÓN}


La dinámica de cambio que sufre la sociedad, ha obligado a que los procesos del desarrollo humano mantengan y mejoren tanto el aspecto cualitativo como cuantitativo. . El proceso educativo no escapa de este desenvolvimiento y desarrollo social, por ello el papel que debe cumplir el la educación en la sociedad obliga a revisar los objetivos para mejorar la calidad de la enseñaza, para abrir un espacio a la crítica, a la autorreflexión

La universidad es un centro de cambio, un cambio tiene significado, cuando la orientación permita un enfoque humanístico tratando de encauzar y desarrollar potencialidades, que promuevan aprendizajes significativos. por eso el impulso de la educación es fundamental para el desarrollo de la sociedad. .

El impacto social, que provocan los esquemas neoliberales repercuten en el desenvolvimiento de la estructura educativa, Es necesario destacar que el compromiso de la educación se centra, en poner de manifiesto la realidad objetiva y compartir los conocimientos críticamente, tomando en cuenta que el hombre no puede ser convertido en un instrumento del otro.

Educar no es imponer esquemas ideológicos, sino despertar en el estudiante inquietudes que reflejen su propio compromiso dentro del contexto social, como una forma sistemática que define al hombre integral y equilibrado en su maduración como persona y socialización adecuada.

Jaime Bustamante en su evolución cultural acumuló y desarrollo conocimientos y ejerció sus facultades intelectuales, lo que le permitió tener una concepción de su propio ser, comprender el medio y elementos que le rodean e interviene en su vida, Jaime poseía conciencia del valor y una voluntad que le permitió tomar a los valores como fines de coacción en el mundo y una forma de pensamiento que lo lleva a una idea particular de libertad.

En el marco del avance del modelo liberal, el proceso de globalización, el debilitamiento del Estado, el expansionismo del capital internacional,el endeudamiento externo e interno y las imposiciones foráneas que abarcan diversos campos en la vida nacional, se debe satisfacer las necesidades de una demanda educativa, cada vez más diversificada y a la par, enfrentar los desafíos del mundo moderno.

La enseñanza que nos ha dejado Jaime es sobre el análisis entre educación, conocimiento y sociedad, es donde el capital humano sea capaz de producir intelecto, generando un mejoramiento en la sociedad en general, en donde las ideas deben provenir de los individuos y no del Estado.

\section{CURRICULUM VITAE}

Nombre:

Edad:

Jaime Gonzalo Bustamante Montaño

Fecha de Nac. : $\quad$ 20-7-58 Tarija, Bolivia

Nacionalidad: Boliviana 
Pasaporte No. : $\quad 969002$

Permiso de residencia No. : 86-1121

ESTUDIOS REALIZADOS:

-6 años de estudios Primarios:

Escuela Juan Crisóstomo Carrillo

Cochabamba, Bolivia 1964-1970.

-6 años de estudios Secundarios:

Colegio Metodista Instituto Americano

Cochabamba, Bolivia 1971-1977.

-Bachillerato en Humanidades:

Universidad Mayor de San Simón UMSS

Cochabamba, Bolivia 1978.

-2 años de Estudios Universitarios

Carrera de Sociología UMSS

Cochabamba, Bolivia 1978-1980.

-1 1/2 años de Estudios Universitarios:

Escuela de Sociología UNA

Heredia, Costa Rica 1983/1985.

OTROS ESTUDIOS:

Curso-Taller Recuperación Histórico-cultural Experiencias de Sistematización Metodológica.

Centro de Investigación para la Promoción Campesina CIPCA.

Cochabamba/ Sucre, Bolivia 1977.

Historia de los movimientos sociales urbanos (sujetos políticos y mov. popular) Centro de Estudios y Promoción del Desarrollo DESCO.

Perú, 1978

Seminario Diseño e implementación de proyectos populares alternativos.

CIPCA / KHANA / CANATA

La Paz, Bolivia, 1978

Taller-Seminario La investigación participativa y acción popular Instituto Politécnico Tomas Katari / Cultura Popular Kanata (hoy Juan Wallparrimachi) / CIPCA

Potosí, Bolivia, 1979.

Metodología y Técnicas de Educación Popular

TAREA / CELADECLima, Perú 1979-1980.

Cultura Popular y Comunicación Alternativa (De lo popular a lo masivo en la cultura de masas) Curso 
Centro de Producción Cinematográfica UKAMAU

La Paz, Bolivia, 1979.

Primer Taller sobre Técnicas y Métodos de Alfabetización Inesita Dimas ANDES 21 de junio (Asociación Nacional de Educadores Salvadoreños) San José, Costa Rica 1982.

Curso Taller de Formación Bíblico-teológico y Pastoral DDET Departamento Ecuménico de Investigaciones

San José, Costa Rica, 1982.

Segundo Taller de creatividad: Experiencias de concepción metodológica.

RED ALFORJA (IMDEC, CEASPA, CENCOP, CEPA)

Nicaragua-San José, Costa Rica, 1983.

Cursos varios de Capacitación Pastoral (Nuevo Testamento, Evangelización y Reino de Dios; Administración Pastoral)

PRODIADIS y CURSOS de Extensión

Seminario Bíblico Latinoamericano SBL, 1983

Curso La radio en la comunicación de Adultos. Taller de producción de materiales didácticos

UNED / MEP / OEA / CEMEDA

San José, Costa Rica, 1983

Taller sobre la historia de la Iglesia en América Central CEHILA - Comisión de Estudios de Historia de la Iglesia en Latino América San José, C. R. 1984

Seminario / Taller Comunicación Popular, participación y democracia Consejo superior Universitario Centroamericano CSUCA

San José 1984

TALLERES VARIOS DE COMUNICACION, EDUCACION, PROMOCION ORGANIZATIVA POPULAR CENAP / VECINOS / ALFORJA / CECADE / ILPEC

Curso Taller: Proyectos de Iniciativa popular Cambio y desarrollo CRES/ Taller Permanente de Concertación y Alternativas Regionales 1985

Iniciativas populares de respuesta a la crisis, Cooperativismo y Cambio 
Instituto Cooperativo Interamericano, ICl, Panamá

Tercer encuentro sobre Diseño, Implementación y Evaluación de Proyectos Asociación Latinoamericana de Organizaciones Populares ALOP San José, Costa Rica, 1986

\section{EXPERIENCIAS DE TRABAJO:}

CULTURA POPULAR KANATA (Hoy Centro de Comunicación Juan Wallparrimechi)

1975-1978 Miembro del equipo de Comunicación y Producción de Materiales

Experiencia de campo con pobladores urbanos.

Cochabamba-Bolivia

INSTITUTO POLITECNICO TOMAS KATARI / CENTRO DE INVESTIGACION Y PROMOCION CAMPESINA CIPCA

1978-1980 Trabajo de promoción en organización social para la producción y educación popular.

Ocuri Norte de Potosí, Bolivia

ASAMBLEA PERMANENTE DE DERECHOS HUMANOS

Colaborador y activista.

PRIMERA IGLESIA BAUTISTA "CALAMA"

$1976 \quad$ Trabajo de pastoral juvenil

Cachabamba, Bolivia

IGLESIA BAUTISTA DE DESAMPARADOS

1982 Trabajo de extensión pastoral comunitaria, responsable de educación cristiana.

San José, Costa Rica

CENTRO POPULAR DE EDUCACION VECINOS

1982-1986 Miembro del colectivo de dirección.

Responsable de los programas: Formas organizativas $y$ Documentación y Publicaciones.

San José, Costa Rica

CENTRO DE INVESTIGACIONES CENTROAMERICANAS Y DE AYUDA HUMANITARIA

1986-1987 Miembro del colectivo de análisis y seguimiento a la coyuntura. Investigador del área Urbana y Campesina

San José, Costa Rica 
INSTITUTO LATINOAMERICANO DE PEDAGOGIA DE LA COMUNICACION (ILPEC)

FONDO DE LAS NACIONES UNIDAS PARA LA INFANCIA (UNICEF)

1986

Intercambio de experiencias entre distintos grupos productivos.

San José, Costa Rica 
De ustedes con mis más atentos saludos

Jaime Bustamante $M$.

\section{Bibliografía}

Arnal, Justo y otros. Investigación Educativa. Fundamentos y

Metodologías 1994. Ed. Labor. Barcelona. España.

Bustamante Jaime. Documentos. 1993.

Dobles, Ma. Cecilia y otros. Investigación en Educación. 1995.

Ed. Euned. Costa Rica

Documentos de La Asociación Ecologísta Costarricense. Facilitados por Alvaro León Chavez

Estatuto Orgánico. . de la Universidad. Editorial Universidad de Costa Rica 1995.

Henning, Jensen. Universidad Ciencia y

Humanismo. 1995. ED. Tecnociencia.

San José. Costa Rica.

Herrera, Rosalila y otra. Universidad y Reformismo en Costa Rica.

1994. Editorial Universidad de Costa Rica.

Maradiaga,David. Dejen al Sol brillar. 1192. El Productor S. R. L. San José, Costa Rica.

Quintina,Martín. La Organización de Centros Educativos en una perpectiva de cambio. 1996. Ed. Sanz y Torres. Madrid España.

Entrevista : Sr. Alvaro León Chavez. Julio 2001 